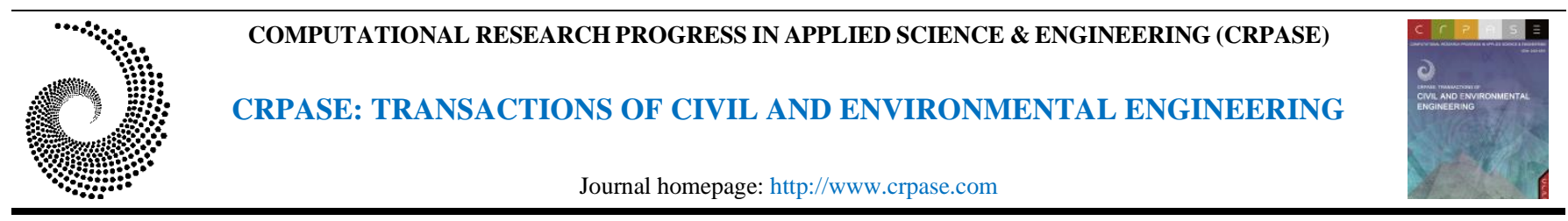

CRPASE: Transactions of Civil and Environmental Engineering 8 Article ID: 2222, 1-6, Special Issue: NCTT 2021

ISSN 2423-4591

Research Article

\title{
Investigating the Effect of Personal Characteristics of Passenger Car On-street Parking Violations (Case Study: Rasht City)
}

\author{
Iraj Bargegol*, Sobhan Hassanjani \\ Department of Civil Engineering, Faculty of Engineering, University of Guilan, Rast, Iran
}

\begin{tabular}{ll}
\hline Keywords & Abstract \\
\cline { 2 - 3 } $\begin{array}{l}\text { Double park, } \\
\text { Double park violation, } \\
\text { On-street parking, }\end{array}$ & $\begin{array}{l}\text { Today, the problem of lack of parking space, especially in the central areas of the city, } \\
\text { plagues most large cities. Drivers are always looking for a suitable place to stop their } \\
\text { Park distance, } \\
\text { Driver personal } \\
\text { characteristics. }\end{array}$ \\
$\begin{array}{l}\text { road, and how to park it is considered as one of the factors affecting the performance of the } \\
\text { road. Also, many factors affect the duration of park maneuvers in the margins of the } \\
\text { passages, which disrupts the saturation flow rate passing through the passage. Therefore, it } \\
\text { is important to study the effect of on-street parking on the performance of main } \\
\text { thoroughfares. The present study was conducted to investigate the effect of personal } \\
\text { characteristics of passenger car drivers on on-street parking violations. In this regard, } 4 \\
\text { streets in Rasht city (Lakani, Golsar, Nawab, Takhti) were selected based on different } \\
\text { objectives. Also, the peak hours were determined by examining the peak time through live } \\
\text { traffic images on Google. Variables such as driver age, sex and coverage, park distance, } \\
\text { intersection, vehicle, pick-up time and weather condition were considered as possible factors } \\
\text { affecting the double park violation. As a result, the longest park distance recorded at } 1013 \\
\text { is } 150 \text { to } 250 \text { meters, which indicates that there is no parking space on the streets per se. } \\
\text { Also, most of the double park violations take place in rainy weather, which shows the effect } \\
\text { of rain on the double park violation. }\end{array}$ \\
\hline
\end{tabular}

\section{Introduction}

Parking management is one of the main components of traffic management as the problem of lack of parking space plagues most large cities. Lack of on-street parking lots leads to an increase in on-street parking and a decrease in street width and overall disruption of the traffic system. In addition, it should be noted that parking on the sidewalks imposes a high cost on the urban community, despite the small benefits it has for car owners [1]. A simple comparison shows how a car takes up a lot of space in the city; a standing person occupies approximately 0.180 square meters of surface area and needs about 0.55 square meters of surface area when moving or sitting. A one-story bus needs about 23.5 square meters of land at the stop, which due to its average capacity, this level is calculated to be 1.2 square meters per passenger. Obviously, this level is halved for a double-decker bus. It may seem that by building large parking lots in suitable neighborhoods, the problem of parking can be solved, but considering the obstacles and administrative problems and the consequences of creating parking lots that meet only a few needs, it is concluded that it can not be done without considering all aspects of the city traffic problem overcame the parking problem [2]. The construction of large and possibly multi-storey car parks, such as in places like city centers, which often face a lack of space to stop vehicles, is costly due to the limited and

\footnotetext{
* Corresponding Author: Iraj Bargegol

E-mail address: Bargegol@guilan.ac.ir
}

Received: 12 November 2021; Revised: 12 December 2021; Accepted: 11 January 2022 https://doi.org/10.52547/crpase.8.2222

Academic Editor: Mahdi Feizbahr

Please cite this article as: I. Bargegol, S. Hassanjani, Investigating the Effect of Personal Characteristics of Passenger Car On-street Parking Violations (Case Study: Rasht City), Computational Research Progress in Applied Science \& Engineering, CRPASE: Transactions of Civil and Environmental Engineering 8 (2022) 1-6, Article ID: 2222. 
expensive land. In most cases, even if there is sufficient budget and credit for various reasons such as ancient buildings or the destruction of the original texture of the city, developing enough parking in city centers and places that have restrictions in terms of vehicle traffic and traffic density increase traffic problems due to more traffic attraction.

\section{Previous Studies}

In Sydney, Australia, Wijayaratna conducted a study on the effect of on-street parking on the capacity of sidewalks in 2015. Data in 6 areas of Sydney based on car parking time were considered as half-hour, one-hour and two-hour parks, each of which was collected on 2 working days of the week and during peak hours. The results showed that the duration of car parking affects the capacity of the line adjacent to the on-street parking. The shorter the parking time, the higher the percentage reduction in capacity due to the on-street parking, and in contrast, if the car park is the same as the entire 24-hour period, the effect on the capacity of the car will be minimal [1].

In 2015, Bargegol et al. in a study investigated the effect of the number of stops and on-street parking of inner-city taxis on the traffic of the exit branch of signalized intersections in Rasht. This research was performed on 4 intersections of Rasht city and the required information was obtained by filming and recording with a stopwatch in accordance with the Highway Capacity Manual (HCM) in the evening hours in order to determine the impact coefficients of the on-street parking and taxi station [3].

Bargegol and Gilani (2015) conducted another study to investigate the effect of rainy weather on the walking speed of pedestrians on sidewalks. The results obtained from this research indicate that the average amount of parking maneuvering time is a function of the width of the lane and with decreasing the lane width, the time required to perform the parking maneuver at the sidewalk increases [4].

Bargegol examined the delay modeling of un-signalized roundabouts using neural network and regression. The main goal in this study is to investigate and predict the effects of on-street parking on the poor performance of urban traffic. They used the cellular automata model to study and simulate lane change by cyclists. To do this, they defined two types of collisions between cars and bicycles according to the width of the bicycle path, friction interference and interference with blockage. According to the results, the amount of frictional and blocking collisions is related to the volume of cars and cyclists, and also in wider crossings, frictional collisions are generally and in narrow passages, the number of blocking collisions is higher [2].

In 2016, Gao and Ozbay modeled the impact of a double park on urban streets. The data collection was done through field data and video recording. The results showed that the duration of the double parking event and the overall traffic demand have a significant effect on the average travel time [5].

In 2007, Galatioto and Bell in case studies in Boston (USA), Parma (Italy), and Rio de Janeiro (Brazil) examined the prevalence of illegal parking behavior depending on the type of vehicle. Illegal parking affects traffic flow, especially in terms of congestion, increases delays and queues. As a result, it helps increase the concentration of pollutants in urban areas. The results show how double illegal parking increases congestion, delays, and queues. This clearly shows that illegal parking can be modeled on a microscopic model. These features have acquired the characteristics of driver behavior in terms of time, duration, and causes of the illegal parking event. Generally, these events are with travelers with lunch in cafes and bars and shoppers in small retail stores. Also, the parking time was typically 12 minutes and lasted a maximum of 1 hour [6].

In 2018, Małecki in a study entitled "A computer simulation of traffic flow with on-street parking and drivers' behavior based on cellular automata and a multi-agent system" examined the on-street parking and parking space along the street in a line of the passage dedicated to this work. The effect of this type of parking lot on traffic flow as well as travel time and speed was also examined. This study was conducted in Szczecin, Netherlands, and examined drivers' behavior during park operations along the street, including their patience, awareness, and vigilance, as well as the use of traffic signs. In this study, all the elements mentioned in the simulation software have been simulated and investigations have been performed on them Based on the obtained results, it was shown that drivers' patience is a positive factor and of course, it affects the traffic, so that when changing the car lane, this factor increases the driver's comfort and also causes more order, and this is while excessive patience (in case the speed reduces the speed of operation) can itself be a factor in increasing traffic and urban congestion. The simulation showed that controlling patience while relaxing in a way that does not reduce speed and efficiency is very acceptable [7].

Another acceptable indicator is drivers' eyesight, which reduces traffic congestion, and the use of a route guide can have a positive effect on drivers' driving. It was further mentioned that in order to design a place for car parking, the parking guide system can be used, which is very valuable and efficient and has positive effects on the capacity of the passage, especially when all the places for the park are full [8].

Cao et al. (2013), in a case study in Zurich, Switzerland, examined and found the shortest distance from an intersection where a suburban park is less likely to delay traffic. In many cases, the number of delays applied to cars in the queue due to on-street parking is very limited, but if it occurs in the vicinity of a traffic signalized intersection, this delay can cause changes and disruptions in one or more cycles. In this research, two types of intersection delays were investigated, delay that causes the stop behind several cycles of the light and delay that normally occurs and causes the back of a light cycle to stop. The purpose of the research was to investigate the conditions under which these delays are applied. This study presented an analytical model to investigate the effects of on-street parking maneuvers on the vicinity of intersections and for this purpose, two indicators of capacity reduction at the intersection and the applied delay were selected, and finally, the value of these two indicators were measured and compared [9].

Tahouni in 2019 analyzed the spatial violations of the parks and their relationship with the points of interest. The selected 
study area is District 6 of Tehran, due to the centrality and occurrence of violations. In other words, government management, decision-making systems, as well as modern economic-commercial systems of the city are located in District 6. A combination of the above factors leads to the demand for regional and urban studies. Based on the data collection, a free Android app called SW Map was used, which applies the phone's built-in GPS with an accuracy of five meters. The accuracy of the system was reliable enough to carry out this project. However, manual inspections were also performed to prevent significant errors. Data were also collected simultaneously to prevent additional errors. Statistical analysis was performed based on the number of types of provinces and comparison of two regions in the study area. With these explanations, they concluded that the number of violations around hospitals increases and differs from the regional average, as park-double and park violations increase significantly around hospitals. While around other POIs, such as a university, the number of legal stops is above the regional average. Violations in parking lots can cause rapid roadblocks [10].

\subsection{Objectives of This Study}

In this study, the effect of personal characteristics of passenger car drivers on the violations of the on-street parking in Rasht, as well as the factors that affect the manner and performance of drivers when parking on the sidewalks, has been investigated. Investigating the relationship between age and sex and coverage, age and climate, age and park distance, sex and coverage with the intersection, climate and collection time, climate and park distance was done in this study.

\section{Methodology}

The purpose of the research topic justifies the research method and tools. Therefore, understanding the nature of research is the first step in choosing research methods and tools. The study of various authorities related to the study of the effect of personal characteristics of drivers of passenger cars on the violations of on-street parking at the intersection, including the goals set in this area, was reviewed. Field studies and data collection were performed using field surveys developed to show the factors affecting vehicles.

\subsection{Study Place}

After obtaining the field collection permit from the respected disciplinary authority, 4 intersections of Rasht city (Golsareh St., Takhti St., Lakani St., Nawab St.) were selected. Figure 1 shows the coordinates of each area.

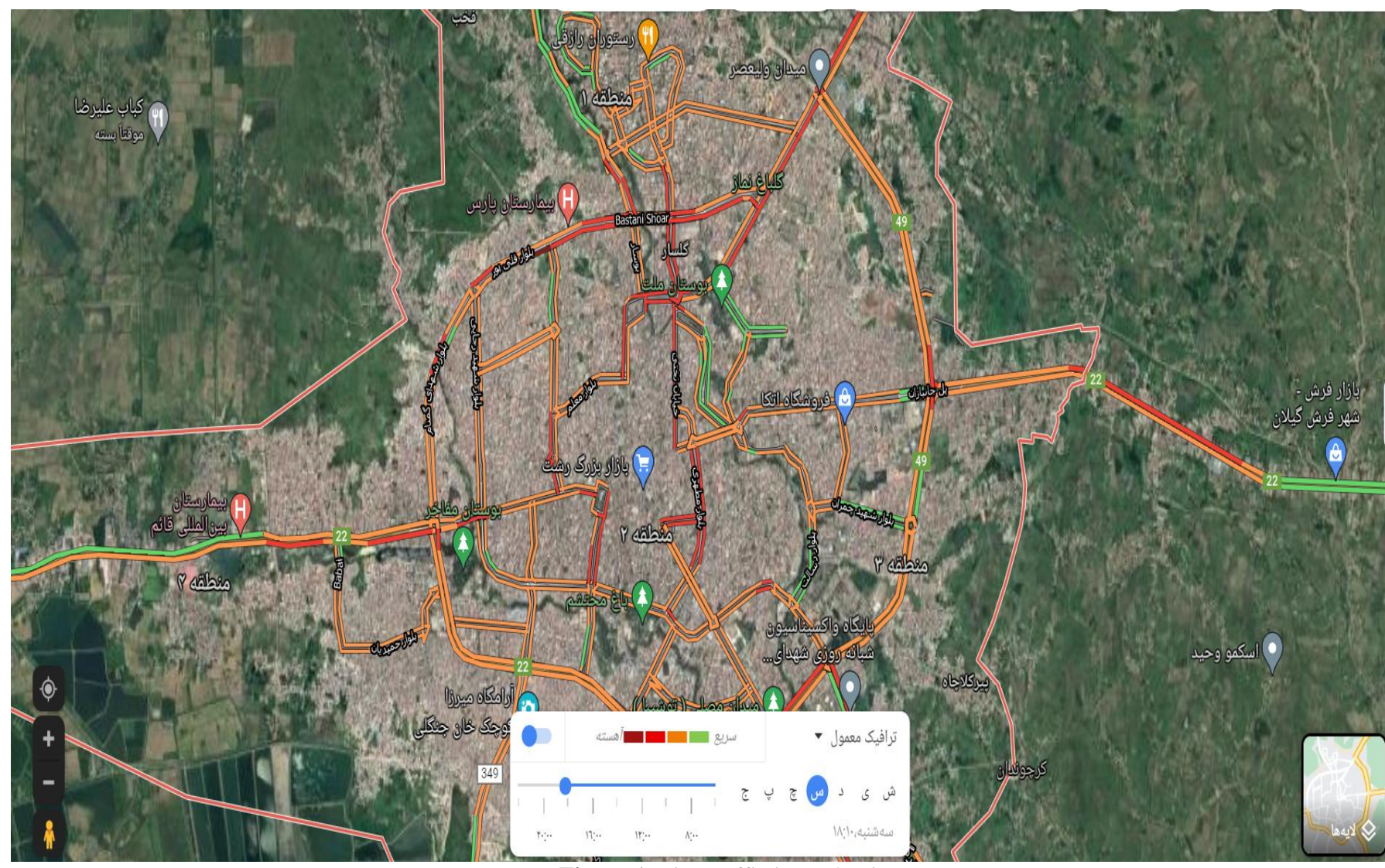

Figure 1. Live traffic in Rasht city 


\subsection{Study Place}

The method of data collection is observational and field statistics. The location of the person was chosen for field surveillance relative to the parking areas of vehicles. The person is in the right position to see the details of the behavior and appearance of the vehicles, the type of movement and how to double park invisibly so that the vehicles do not notice the presence of the person to avoid a possible effect on the behavior of vehicles, given that the details of the behavior and appearance of vehicles are very important in this study. The frequency of passes was counted and manually recorded in tables and then transferred to the software. The process of counting vehicles was done as follows: number of females who did the double park, number of males who did the double park, segregation of vehicles by age, segregation of vehicles by sex and coverage, segregation of vehicles by weight.

\subsection{Analysis Method}

Demographic analysis and comparison of double parking violations in all four streets was performed, the effect of factors, including age, sex and cover, climate, park distance and collection time was examined, and finally, the relationship between them was determined through frequency analysis and analysis of effective factors. In the first place, the peak hours were determined by examining the peak time determination through live traffic images in Google. Then, the streets were chosen based on the purpose of the travel. Data collection was done in a field and intangible, then the information was separated. The method of this research is according to the flowchart of Figure 2.

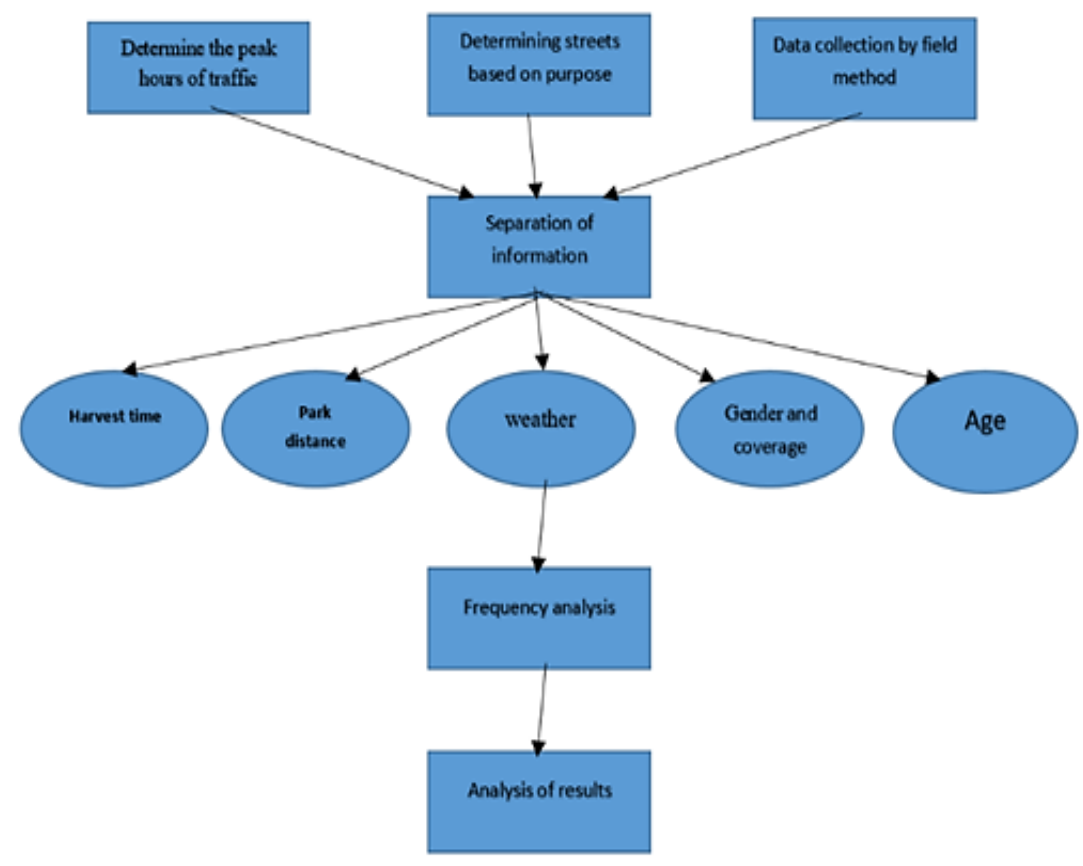

Figure 2. Flowchart of research method

\section{Results}

Table 1 generally shows that the age range of 31 to 45 years in all 4 genders and case coverage with the number of 1067 commit the most violations, followed by two age ranges of 18 to 30 years and 46 to 60 years. 670 and 634, respectively, are almost equal in committing double parking offenses, and the 60-year-olds with 129 have the least offenses.

Table 1. Age breakdown by sex and coverage

\begin{tabular}{|c|c|c|c|c|c|c|}
\hline \multirow[b]{2}{*}{ Variable } & \multirow[b]{2}{*}{ Category } & \multicolumn{4}{|c|}{ Age } & \multirow[b]{2}{*}{ Total sexuality } \\
\hline & & $\begin{array}{c}\text { From } 18 \\
\text { to } 30\end{array}$ & $\begin{array}{c}\text { From } \\
31 \text { to } 45\end{array}$ & $\begin{array}{c}\text { From } \\
46 \text { to } 60\end{array}$ & +60 & \\
\hline \multirow{5}{*}{ Sexuality } & female - hijab & 9 & 19 & 8 & 1 & 37 \\
\hline & female - common & 141 & 205 & 120 & 22 & 488 \\
\hline & male - formal & 228 & 406 & 239 & 51 & 924 \\
\hline & male-common & 292 & 437 & 267 & 55 & 1051 \\
\hline & total age & 670 & 1067 & 634 & 129 & 2500 \\
\hline
\end{tabular}

Table 2 shows the effect of age based on park distance on double parking failure. The longest distance of the registered park with 1013 is related to 150 to 250 meters, which indicates that there is no parking space in the streets by itself. According to the observations made during the data collection, most of the cars parked on every street belong to shopkeepers. As commercial land uses are known as the 
most trip attractors $[11,12]$, the results were in line with expectations. It is the street that deprives others of the opportunity to use municipal services and makes parking a problem for them. Also, according to field observations, the average parking of drivers is 15 to 30 minutes, which means that it does not cause traffic and cars are moving, while shopkeepers park their cars for a long time, and this staticity of the car causes the intermittent flow of park-movement not to occur and causes double parking. Also, $8 \%$ of the double parking violations are related to the distance from 1 to 50 . This negligence is neither the fault of the police nor the unavailability of the park location. This is due to our wrong traffic culture. Just draw a double park.

Table 2. Age breakdown based on park distance

\begin{tabular}{|c|c|c|c|c|c|c|}
\hline \multirow[b]{2}{*}{ Variable } & \multirow[b]{2}{*}{ Category } & \multicolumn{4}{|c|}{ Park distance } & \multirow{2}{*}{$\begin{array}{c}\text { Total } \\
\text { age }\end{array}$} \\
\hline & & $\begin{array}{l}1 \text { to } 50 \\
\text { meters }\end{array}$ & $\begin{array}{c}50 \text { to } 150 \\
\text { meters }\end{array}$ & $\begin{array}{c}150 \\
\text { to } 250 \text { meters }\end{array}$ & +250 meter & \\
\hline \multirow{5}{*}{ Age } & from 18 to 30 & 57 & 131 & 259 & 223 & 670 \\
\hline & from 31 to 45 & 85 & 188 & 434 & 360 & 1067 \\
\hline & from 46 to 60 & 44 & 108 & 270 & 212 & 634 \\
\hline & +60 & 15 & 20 & 50 & 44 & 129 \\
\hline & Total park distance & 201 & 447 & 1013 & 839 & 2500 \\
\hline
\end{tabular}

Table 3 shows the impact of sex and street-based coverage. Females commit the most double parking violations on Nawab Street; in other words, the most common reason for neglect among females is treatment. Males committed the most violations on Lakani Street because males do the most service work. On Golsar Street, females recorded a significant amount with $22 \%$ double parking rebellion, which means that females do a lot of double parking with the aim of shopping and having fun.

Table 3. Sex segregation and coverage based on-street parking

\begin{tabular}{|c|c|c|c|c|c|c|}
\hline \multirow[b]{2}{*}{ Variable } & \multirow[b]{2}{*}{ Category } & \multicolumn{4}{|c|}{ Intersection } & \multirow[b]{2}{*}{$\begin{array}{c}\text { Total } \\
\text { sexuality }\end{array}$} \\
\hline & & $\begin{array}{l}\text { Takhti } \\
\text { Street }\end{array}$ & $\begin{array}{c}\text { Golsar } \\
\text { Street }\end{array}$ & Lakani Street & $\begin{array}{c}\text { Nawab } \\
\text { Street }\end{array}$ & \\
\hline \multirow{5}{*}{ Sexuality } & female - hijab & 10 & 7 & 8 & 12 & 37 \\
\hline & female - common & 86 & 136 & 117 & 149 & 488 \\
\hline & male - formal & 169 & 252 & 240 & 263 & 924 \\
\hline & male - common & 191 & 253 & 319 & 288 & 1051 \\
\hline & total intersection & 456 & 648 & 684 & 712 & 2500 \\
\hline
\end{tabular}

In Table 4, the effect of weather variable and collection time was examined. Due to administrative and educational work, in rainy weather in the second period (17 to 19:30), the highest number of statistics was recorded.

Table 4. Distribution of weather based on collection time

\begin{tabular}{|c|c|c|c|c|c|}
\hline \multirow[b]{2}{*}{ Variable } & \multirow[b]{2}{*}{ Category } & \multicolumn{3}{|c|}{ Collection time } & \multirow[b]{2}{*}{$\begin{array}{c}\text { Total } \\
\text { sexuality }\end{array}$} \\
\hline & & $\begin{array}{c}\text { from } 10 \text { to } \\
12: 30\end{array}$ & $\begin{array}{c}\text { from } 17 \text { to } \\
19: 30\end{array}$ & $\begin{array}{c}\text { from } 19: 30 \text { to } \\
22\end{array}$ & \\
\hline \multirow{4}{*}{ Sexuality } & female - hijab & 314 & 302 & 242 & 37 \\
\hline & female - common & 375 & 409 & 290 & 488 \\
\hline & male - formal & 205 & 165 & 198 & 924 \\
\hline & total intersection & 894 & 876 & 730 & 2500 \\
\hline
\end{tabular}

Table 5 shows that 1 to 50 meters, which is the shortest distance to the park, occurred mostly in rainy weather. This shows the effect of weather condition. In other words, people do this offense more in rainy weather, so much so that they are not willing to park even at short distances, and they do double parking to avoid getting wet. In future studies, the parking short distance can be estimated by the A geographic information system method [13].

Table 5. Distribution of weather condition based on park distance

\begin{tabular}{|c|c|c|c|c|c|c|}
\hline \multirow[b]{2}{*}{ Variable } & \multirow[b]{2}{*}{ Category } & \multicolumn{4}{|c|}{ Park distance } & \multirow[b]{2}{*}{$\begin{array}{c}\text { Total } \\
\text { weather condition }\end{array}$} \\
\hline & & $\begin{array}{l}\text { from } 1 \text { to } \\
50 \text { meters }\end{array}$ & $\begin{array}{l}\text { from } 50 \\
\text { to } 150 \\
\text { meters }\end{array}$ & $\begin{array}{l}\text { from } 150 \\
\text { to } 250 \text { meters }\end{array}$ & $\begin{array}{l}+250 \\
\text { meter }\end{array}$ & \\
\hline \multirow{4}{*}{ Weather condition } & sunny & 62 & 143 & 350 & 303 & 858 \\
\hline & rainy & 102 & 201 & 397 & 374 & 1074 \\
\hline & cloudy & 37 & 103 & 266 & 162 & 568 \\
\hline & total park distance & 201 & 447 & 1013 & 839 & 2500 \\
\hline
\end{tabular}




\section{Conclusion}

After reviewing the obtained analyses, the results indicated that males in the double parking registered more than females and the age range of 31 to 45 years committed the most violations of the double parking with 1067 . The maximum distance of the registered park with 1013 numbers is related to 150 to 250 meters, which indicates that there is no parking space on the streets. The average parking time for drivers was 15 to 30 minutes, which does not cause traffic jams and the cars are moving, while the shop owners park their cars for a long time, and this staticness of the car prevents the intermittent flow of park-movement and causes a double parking. $8 \%$ of double parking violations are related to the distance of 1 to 50 meters, which is neither the fault of the police nor the unavailability of the park site, this is due to the wrong traffic culture. Females commit the most double parking violations on Nawab Street, which means that it is the most common reason for neglect among female therapists. Males commit the most offenses on Lakani Street for the purpose of shopping and services. In Golsar Street, females recorded a significant number of violations with $26 \%$ of double parking violations, in other words, females do a lot of double parking with the aim of shopping and having fun. The main reason why shopkeepers park their cars in front of their property is due to the psychological dimension of society and distrust of society due to numerous thefts. $66 \%$ of park violations occur less than 200 meters from the next parking lot. Most of the double parking violations occur in rainy weather, which indicates the effect of rain on the double parking violation.

\section{Reference}

[1] S. Wijayaratna, Impacts of on-street parking on road capacity. in Australasian Transport Research Forum. 2015.

[2] I. Bargegol, V.N.M.Gilani, M. Ghasedi, M. Ghorbanzadeh Delay modeling of un-signalized roundabouts using neural network and regression. Computational Research Progress in Applied Science \& Engineering 2 (2016) 28-34.
[3] I. Bargegol, , A. Amlashi, and V. Gilani, Evaluation average discharge headway at near-side legs of signalized intersections. Journal UMP Social Sciences and Technology Management 3 (2015) 670-675.

[4] Bargegol, I. and V.N.M. Gilani, The effect of rainy weather on walking speed of pedestrians on sidewalks. Buletin Teknol Tanaman 12 (2015) 217-22.

[5] J. Gao, K. Ozbay. Modeling double parking impacts on urban street. in Transportation Research Board 95th Annual Meeting, 2016.

[6] F. Galatioto, M. Bell. Simulation of illegal double parking: quantifying the traffic and pollutant impacts. in Proc. 4th Int. SIIV Congr. 2007.

[7] K. Małecki, A computer simulation of traffic flow with onstreet parking and drivers' behaviour based on cellular automata and a multi-agent system. Journal of computational science 28 (2018) 32-42.

[8] I. Bargegol, , V. Najafi Moghaddam Gilani, F. Jamshidpour, Relationship between pedestrians' speed, density and flow rate of crossings through urban intersections (case study: rasht metropolis) (RESEARCH NOTE). International Journal of Engineering 30 (2017) 1814-1821.

[9] J. Cao, , N. Vasileios, M. Menendez. On-street parking near the intersections: effects on traffic. in 13th Swiss Transport Research Conference, Ascona, Switzerland, 2013.

[10] Koohpayma, J., et al., Spatial Analysis of Curb-Park Violations and Their Relationship with Points of Interest: A Case Study of Tehran, Iran. Sustainability 11 (2019) 6336.

[11] Effati, M. and M.V. Saheli, Examining the influence of rural land uses and accessibility-related factors to estimate pedestrian safety: The use of GIS and machine learning techniques. International Journal of Transportation Science and Technology, 2021.

[12] M.V. Saheli, M. Effati, Segment-Based Count Regression Geospatial Modeling of the Effect of Roadside Land Uses on Pedestrian Crash Frequency in Rural Roads. International Journal of Intelligent Transportation Systems Research 19 (2021) 347-365.

[13] H. Hariri Asli, M. Arabani, Y. Golpour, Reclaimed Asphalt Pavement Based on a Geospatial Information System, Slovak Journal of Civil Engineering 28 (2020) 36-42. 